\title{
SIGNIFICANCE OF SACRAL INDEX IN ESTIMATION OF SEX IN NORTH INDIAN POPULATION
}

\author{
Kanchan Bisht ${ }^{1}$, Rakesh K. Verma ${ }^{1}$, Archana Rani ${ }^{1}$, \\ Navneet Kumar ${ }^{1}$, Baibhav Bhandari ${ }^{2}$
}

1. Department of Anatomy, King George's Medical University, Lucknow, Uttar Pradesh, India

2. Urban Community Health Centre, N.K Road, Hazratganj, Lucknow, Uttar Pradesh, India

\begin{abstract}
Introduction: For the assessment of sexual dimorphism of human skeleton, pelvis has been used with great accuracy by anthropologists and forensic experts. Sacrum, being an integral part of pelvis, has therefore gained importance. Among the various parameters of sacrum, sacral index is the most reliable one, calculated by the formula: Sacral index=max breadth $x 100 /$ max length of sacrum. This study aimed to determine the significance of sacral index in estimation of sex in north Indian population.

Materials and methods: For the present study, 35 dry human sacrum bones were obtained from the Department of Anatomy, KGMU, Lucknow, out of which 32, free of deformity, were used in study. The bones were first separated as male and female on the basis of their gross features. Maximum length and breadth of sacra were measured using digital sliding Vernier calliper and sacral index was calculated.
\end{abstract}

Results: Mean sacral index was significantly higher in females (109.52) as compared to males (92.37). Sex determination done on the basis of gross features were comparable to that done by calculation of sacral index, except in sacrum no. 5,13,14,15 \&16. Sacrum no. 5,13,14 \&15 were more curved forwards (female feature) while their sacral indices were much lesser (male feature). Sacrum no. 16 had a uniform curvature (male feature) while its sacral index was $>105$ (female feature). Sacrum no. 16 also had only 3 dorsal and ventral foramina, which was a variation.

Conclusions: Sacral index is a reliable criterion for sex determination, useful for anatomical, medicolegal and anthropological purposes.

Keywords: Dimorphism, Sacral index, Foramina, Variation, Pelvis, Anthropology

Address for Correspondence:

Dr Rakesh K Verma, Additional Professor, Department of Anatomy, King George Medical University, Lucknow, Uttar Pradesh, Mobile no: 9455252213 Email - rakesh_gsvm@yahoo.co.in

Date of Receiving: 12 July 2020

Date of Acceptance: 06 August 2020

0970-1842/Copyright @ JAS 2020 


\section{INTRODUCTION}

Sacrum is a flattened triangular bone formed by the fusion of five sacral vertebrae. It forms the posterosuperior part of bony pelvis [1]. As stated by Krogman, accuracy of sex determination can be $95 \%$ with pelvis alone. Sacrum being an integral part of pelvis has thus gained importance [2]. However it is still recommended to use multiple bones for sex determination [3]. Among the various parameters of sacrum, sacral index method has always been the most reliable one [4]. Sacral index is calculated by multiplying the breadth of sacrum with 100 and then dividing with length of the sacrum [3].

\section{MATERIALS AND METHODS}

For the present study, 35 dry human sacrum bones were obtained from the Department of Anatomy, King George's Medical University, Lucknow, Uttar Pradesh, out of which 32 were used which were free of deformity. The bones were first separated as male or female sacra on the basis of gross features. Maximum length and breadth of sacra were measured using Vernier callipers and sacral index was calculated using the formula:

Sacral index $=$ maximum breadth $x$ 100/ maximum length

Maximum length is the distance between middle points on anterosuperior margins of promontory to middle of anteroinferior margin of last sacral vertebrae (Fig. 1). Maximum breadth is the distance between the most distant points on sides of ala of sacrum (Fig. 2).

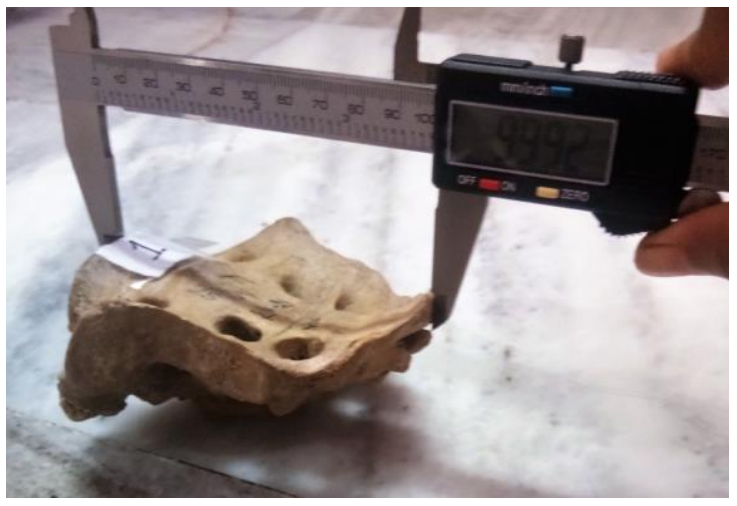

Fig. 1. Measurement of maximum length of sacrum using Vernier calliper.

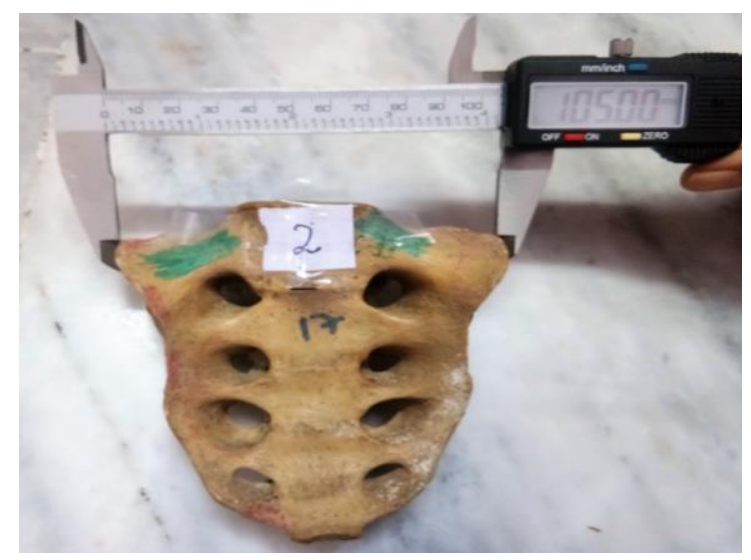

Fig. 2. Measurement of maximum breadth of sacrum using Vernier calliper.

\section{RESULTS}

In this study, mean maximum sacral length of males (111.53) was found to be greater than that of females (93.46). Mean maximum sacral breadth was more or less equal in males and females (102.54 in males and 102.05 in females). However, mean sacral index was observed to be greater in females (109.52) than that in males (92.37). From our study, we can say that sex determination done on the basis of gross features were comparable to that done by calculation of sacral index, except in five sacra. 
Sacra no. 5, 13, 14 \& 15 were more curved forwards (which is a female feature) while their sacral indices were much lesser (which suggests male feature). Sacrum no. 16 had a uniform curvature (male feature) while its sacral index was >105 (female feature). This sacrum had only 3 dorsal and ventral sacral foramina, which was a unique variation.

\section{DISCUSSION}

Although various parameters of sacrum can be used for sex estimation, sacral index has always been the most reliable one. In our study, we observed the mean sacral length of males to be greater than that of females, which is in accordance with various studies done in many

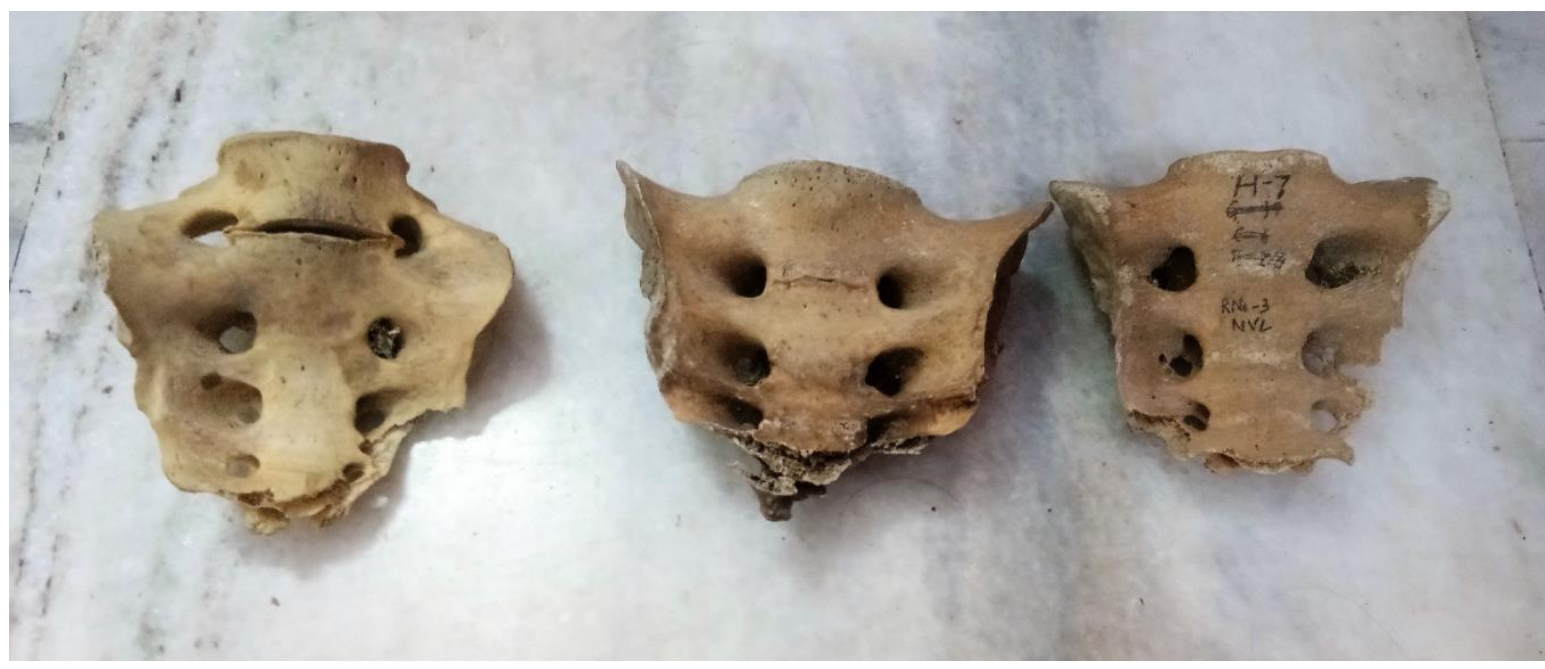

Fig. 3. Bones no. 33, 34 \& 35 fragmented and deformed

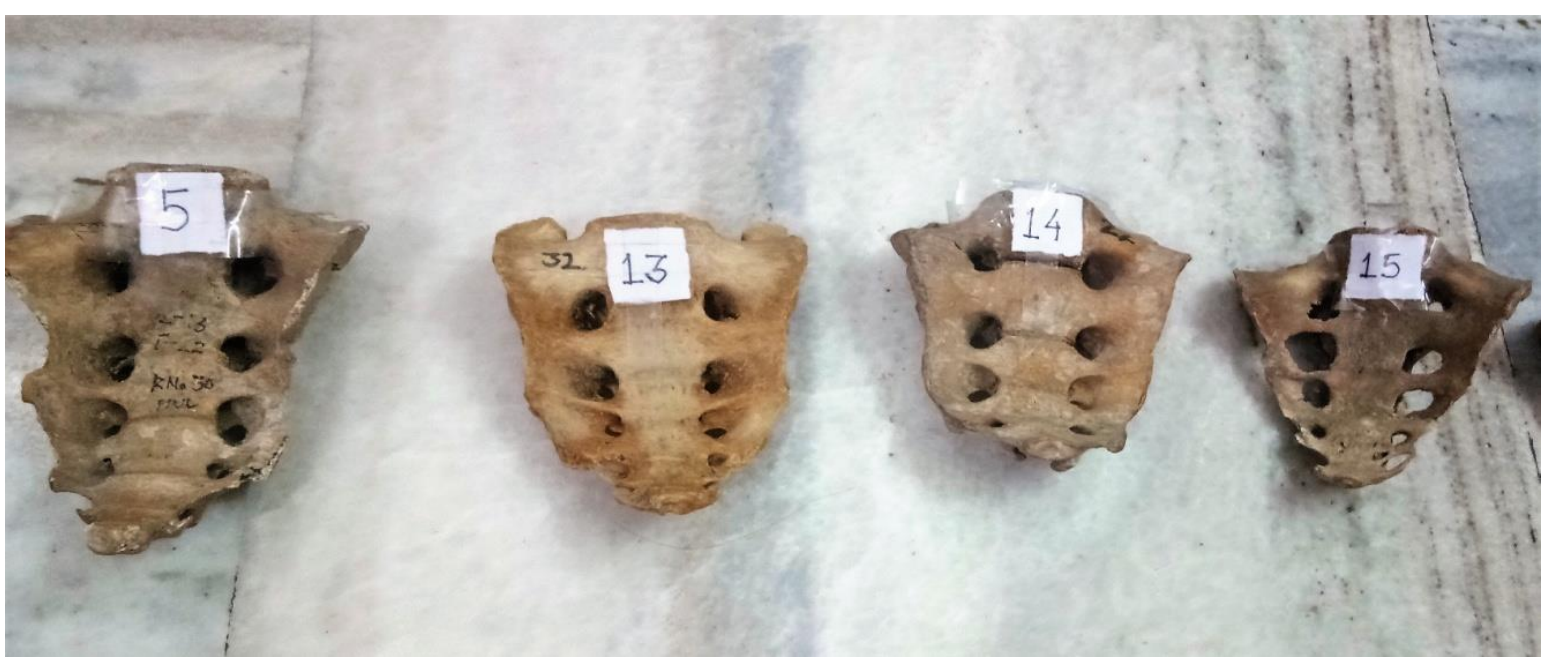

Fig. 4. Sacra with sacral indices not comparable to their gross features 


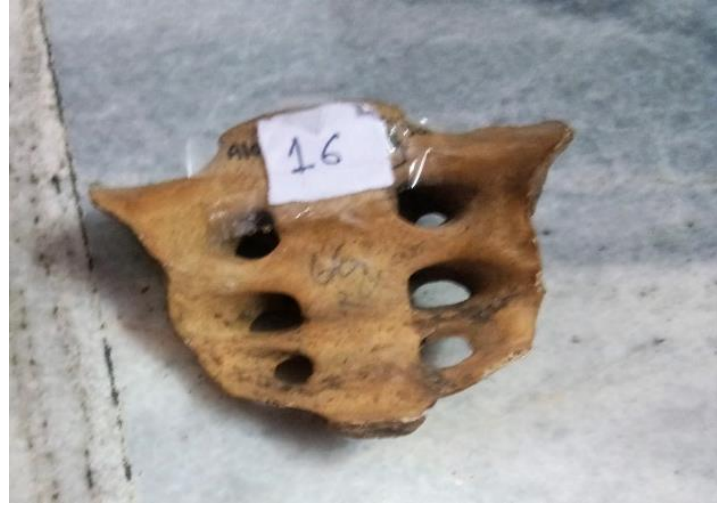

Fig. 5. Sacrum with abnormal sacral foramina

different populations. Increased incidence of six-piece sacrum in males has been proposed to be one of the causes behind the same [3].

Maddikunta et al. recorded the mean sacral breadth in males to be 104.2 and 103.4 in females in his study on the population of Andhra Pradesh [5]. Ravichandran et al. carried out a study in Tamil Nadu and found this value to be 93.7 in males and 92.91 in females [3]. A similar study done by Yadav et al. in Maharashtrian population also observed comparable values of mean sacral breadth in males (102.93) and females (104.7) [1]. Values obtained by Somesh et al. in Mangalore were also not very much different (105.21 in males and 102.66 in females)[6]. Two different studies were conducted in Madhya Pradesh in the same year 2016 in which one conducted by Dubey et al. on 60 sacra found almost similar mean sacral breadth in males and females [2]. In the second one, conducted by Punase et al. on 77 sacra, mean sacral breadth of females was found to be significantly higher than that of males (113.27 in females and 105.05 in males) [7].

Findings of Masih et al. and Parashuram et al. in different studies performed in Rajasthan and Karnataka, also agree with that of our present study, showing almost similar mean sacral breadth in both the sexes [4,8]. However, Sachdeva et al. in 2011, found a significantly higher mean breadth of sacra in males than that in females, which is in contrast to our present study [9].

All the above-mentioned studies, however, are in accordance with our study if we compare the sacral index of both the sexes, implying that

\begin{tabular}{|l|l|l|l|l|l|l|l|l|}
\hline \multicolumn{1}{|c|}{ Study } & \multicolumn{1}{|c|}{ Place } & $\begin{array}{c}\text { Total } \\
\text { bones }\end{array}$ & $\begin{array}{c}\text { Males } \\
(\mathbf{L})\end{array}$ & $\begin{array}{c}\text { Males } \\
(\mathbf{B})\end{array}$ & $\begin{array}{c}\text { Females } \\
(\mathbf{L})\end{array}$ & $\begin{array}{c}\text { Females } \\
(\mathbf{B})\end{array}$ & $\begin{array}{c}\text { SI in } \\
\text { males }\end{array}$ & $\begin{array}{c}\text { SI in } \\
\text { females }\end{array}$ \\
\hline Sachdeva et al. & Amritsar & 50 & 104.1 & 111.8 & 91.8 & 104.4 & 100.24 & 111.74 \\
\hline Maddikunta et & Andhra & 60 & 113.9 & 104.2 & 90 & 103.4 & 91.8 & 116.3 \\
\hline Ravichandran et & Tamil Nadu & 123 & 97.8 & 93.7 & 90.96 & 92.91 & 96.32 & 102.29 \\
\hline Yadav et al. & Maharashtra & 140 & 104.7 & 102.93 & 92.6 & 104.7 & 98.44 & 113.23 \\
\hline Somesh et al. & Mangalore & 87 & 113.88 & 105.21 & 91.29 & 102.66 & 92.71 & 113.06 \\
\hline Dubey et al. & Madhya & 60 & 113.5 & 105.85 & 94.6 & 104.33 & 93.8 & 110.63 \\
\hline Punase et al. & Madhya & 77 & 111.86 & 105.05 & 99.10 & 113.27 & 95.66 & 115.10 \\
\hline Masih et al. & Rajasthan & 75 & 107.44 & 104.63 & 97.88 & 102.77 & 97.88 & 112.69 \\
\hline Parashuram et & Karnataka & 100 & 120.13 & 124.61 & 103.78 & 118.45 & 101.26 & 116.18 \\
\hline Present study & Lucknow & 32 & 111.53 & 102.54 & 93.46 & 102.05 & 92.37 & 109.52 \\
\hline
\end{tabular}

Table 1. Comparative analysis of sacral measurements 
sacral index of females is almost always higher than that of males $[10,11]$.

\section{CONCLUSION}

It is evident from the present study that sacral index is a reliable and significant criterion for estimation of sex in a given population. However, it is still recommended to use multiple bones and parameters for this purpose. Thus, regional and racial differences in sacrum along with the sacral index can be useful for anatomical, medico-legal and anthropological purposes.

\section{REFERENCES}

1. Yadav N, Saini K, Patil K. Determination of sex using dry adult human sacrum- a morphometric study. Int $\mathrm{J}$ Cur Res.2015;7(3):22-27.

2. Dubey A, Roy SS, Verma S. International Journal of Anatomy and Research. 2016; 4(1):2096-98.

3. Ravichandran D, Shanthi KC, Shankar K, Chandra H. A study on sacral index in Tamil Nadu and Andhra Pradesh population of Southern India. Journal of Clinical and Diagnostic Research. 2013;7(9): 1833-1834

4. Masih WF, Singh AP, Rathore KB. Significance of sacral index in estimation of sex of sacrum Inhadoti Rajasthan. Acta Scientific Dental Sciences. 2017; 02-05.

5. Maddikunta V, Ravinder M. International Journal of Research in Medical Sciences.2014;2(1):164-174.

6. Somesh MS, Sridevi HB, Murlimanju BV. An anatomical study of adult sacrum with its emphasis on its sexual dimorphism in South Indian population. 2015;3(4):1491-96.

7. Punase VK, Agrawal NL, Shrivastava SK. A morphometric study on dry adult human sacrum for determination of sex. Paripex Indian journal of research. 2016;5(3):368-9.

8. Parashuram R, Dakshayani $K R$, Manjunatha SN. A study of sacral index: A basis for determination of sex of sacrum. Int J Anat Res.2018; 6(4.2):5873-77.

9. Sachdeva K, Singla RK, Kalsey G, Sharma G. Role of sacrum in sexual dimorphism- A morphometric study. J Indian Acad Forensic Med. 2011; 33(3):206-210.

10. Arora AK, Gupta P, Mahajan S, Kapoor SS. Significance of sacral index in estimation of sex in sacra of cadavers in Punjab. J Indian Acad Forensic Med:32(2).

11. Patel S, Nigam M, Mishra P, Waghmare CS. A study of sacral index and its interpretation in sex determination in Madhya Pradesh. $\mathrm{J}$ Indian Acad Forensic Med. 2014; 36(2). 